Pesq. Vet. Bras. 36(Supl.1):33-40, junho 2016 DOI: 10.1590/S0100-736X2016001300005

\title{
Transferência de imunidade passiva e proteinograma sérico em bezerros das raças Crioula Lageana variedade Mocha e Aberdeen Angus (Red Angus) nos primeiros seis meses de vida ${ }^{1}$
}

\author{
Jackson Schade ${ }^{2}$, Renato M. Rossi ${ }^{3}$, Graziela V. Fonteque ${ }^{4}$, Edison Martins ${ }^{5}$, Júlio \\ A.N. Lisbôa ${ }^{6}$, Karina K.M.C. Flaiban ${ }^{7}$, Maria C.P. Preti ${ }^{7}$ e Joandes H. Fonteque ${ }^{8 *}$
}

\begin{abstract}
Schade J., Rossi R.M., Fonteque G.V., Martins E., Lisbôa J.A.N., Flaiban K.K.M.C., Preti M.C.P. \& Fonteque J.H. 2016. [Transfer of passive immunity and serum proteinogram in calves of the Criollo Lageano hornless variety and Aberdeen Angus (Red Angus) breed in their first six months of life.] Transferência de imunidade passiva e proteinograma sérico em bezerros das raças Crioula Lageana variedade mocha e Aberdeen Angus (Red Angus) nos primeiros seis meses de vida. Pesquisa Veterinária Brasileira 36(Supl.1):33-40. Departamento de Medicina Veterinária, Centro de Ciência Agroveterinárias, Universidade do Estado de Santa Catarina, Av. Luiz de Camões 2090, Lages, SC 88520-000, Brazil. E-mail: fonteque@hotmail.com

The Criollo Lageano breed is an alternative for modern farming, due to its high genetic variability, rusticity and adaptation to environmental conditions of the Plateau of Santa Catarina, Brazil. These characteristics can influence important physiological events which should be investigated, because they can assist in developing future programs of animal breeding. It is known that failure of passive transfer (FPT) is an important factor for the increase in neonatal mortality in cattle. Thus, it is essential to evaluate aspects related to FPT in Criollo Lageano calves and the comparison with other beef breed created in the Plateau of Santa Catarina. Aiming to evaluate and to compare the passive transfer of immunity and serum protein concentrations, two experimental groups of 11 calves of Criollo Lageano (CL) hornless variety and 14 Aberdeen Angus (Red Angus) calves were selected. Blood samples were collected by jugular venipuncture for the measurement of total serum protein (TSP) by serum protein electrophoresis in agarose gel and the activity of gamma glutamyl transferase (GGT) and concentration of immunoglobulin G (IgG) by the method of the turbidity zinc sulphate, between 24 and 36 hours, 15, 30, 60, 90, 120, 150 and 180 days. Statistical analysis of data was performed by analysis of variance (ANOVA), Tukey test for comparison of means $(\mathrm{P}<0.05)$ and correlation between variables. Values of TSP, globulins, immunoglobulins, IgG and serum GGT activity at birth (24-36 hours) confirmed that there was adequate TIP with no significant difference between the races, except for the serum GGT activity. Physiological variations in the curve of serum proteins from birth to 180 days of age were identified. Strong positive correlation was found between the values of gamma
\end{abstract}

\footnotetext{
${ }^{1}$ Recebido em 20 de junho de 2015.

Aceito para publicação em 18 de janeiro de 2016.

${ }^{2}$ Acadêmico de Medicina Veterinária, Bolsista de Iniciação Científica (PROBIC/UDESC), Departamento de Medicina Veterinária, Centro de Ciências Agroveterinárias (CAV), Universidade do Estado de Santa Catarina (UDESC), Av. Luiz de Camões 2090, Bairro Conta Dinheiro, Lages, SC 88520-000, Brasil.

${ }^{3}$ Acadêmico de Medicina Veterinária, Bolsista de Iniciação Científica (PIVIC/UDESC), Departamento de Medicina Veterinária, Centro de Ciências Agroveterinárias (CAV), Universidade do Estado de Santa Catarina (UDESC), Lages, SC 88520-000, Brasil.

${ }^{4}$ Docente do Centro Universitário Facvest, Av. Marechal Floriano 947, Lages, SC 88501-103, Brasil.
}

\footnotetext{
${ }^{5}$ Médico Veterinário Dr. Superintendente do Serviço de Registro Genealógico da raça Crioula Lageana. Associação Brasileira dos Criadores da Raça Crioula Lageana (ABCCL), Rua Correia Pinto 22, sobreloja, Lages, SC 88502-901, Brasil

${ }^{6}$ Docente do Departamento de Clínicas Veterinárias (CCA), Universidade Estadual de Londrina (UEL), Campus Universitário, Cx. Postal 6001, Londrina, PR 86051-990, Brasil.

${ }^{7}$ Médica Veterinária, Residente do Programa de Residência em Medicina Veterinária: Área de Patologia Animal, Departamento de Medicina Veterinária Preventiva (DMVP), UEL, Campus Universitário, Cx. Postal 6001, Londrina, PR 86051-990, Brasil

${ }^{8}$ Docente do Departamento de Medicina Veterinária, CAV-UDESC, Av. Luiz de Camões 2090, Bairro Conta Dinheiro, Lages, SC 88520-000, Brasil. *Autor para correspondência: fonteque@hotmail.com
} 
globulin and IgG ( $\mathrm{r}=0.814$ and $\mathrm{r}=0.877$ for CL to AA), PTS ( $\mathrm{r}=0.783$ and $\mathrm{r}=0.947$ for CL to $\mathrm{AA}$ ), globulins ( $\mathrm{r}=0.945$ and $\mathrm{r}=0.985$ for CL to AA), indicating that these variables will be good indicators of TIP in calves at the second day of life (24-36 hours). The correlation between gamma globulin and activity of GGT was weakly positive ( $\mathrm{r}=0.251)$ for CL and strongly positive ( $\mathrm{r}=0.815$ ) for the Aberdeen Angus (Red Angus), in which a wide variation in GGT values after 24 hours of life of the calf were noticed. No difference was found in FPT between Criollo Lageano hornless variety and Aberdeen Angus (Red Angus), and was successful way in both breeds. It can be suggested that Criollo Lageano hornless variety breed is later in active antibody synthesis, highlighting the precocity of taurine evident in Aberdeen Angus (Red Angus) breed.

INDEX TERMS: Cattle, immunoglobulins, passive immunity, serum proteins.

RESUMO.- A raça Crioula Lageana apresenta-se como uma alternativa para a pecuária moderna, devido a sua grande variabilidade genética, rusticidade e adaptação às condições ambientais do Planalto Catarinense. Estas características podem influenciar importantes eventos fisiológicos, os quais deveriam ser investigados, pois podem auxiliar no desenvolvimento de futuros programas de melhoramento animal. Sabe-se que a falha da transferência de imunidade passiva (TIP) constitui um importante fator para a elevação dos índices de mortalidade neonatal na espécie bovina. Desta forma, torna-se indispensável à avaliação dos aspectos relacionados à TIP em bezerros da raça Crioula Lageana variedade mocha e a sua comparação com outras raças de corte criadas no Planalto Serrano Catarinense. Com o objetivo de avaliar e comparar a TIP e o proteinograma sérico foram selecionados dois grupos experimentais compostos por 11 bezerros da raça Crioula Lageana variedade mocha e 14 bezerros da raça Aberdeen Angus (Red Angus). Amostras de sangue foram colhidas por meio da venopunção jugular para a mensuração da proteína total sérica (PTS), eletroforese das proteínas séricas em gel de agarose, atividade da gamaglutamiltransferase (GGT) e concentração de imunoglobulinas $\mathrm{G}(\operatorname{IgG})$ por meio do método de turvação pelo sulfato de zinco nos períodos entre 24 e 36 horas, 15, 30, 60, 90, 120, 150 e 180 dias de vida. A análise estatística dos dados foi realizada por meio da análise de variância de medidas repetidas (ANOVA), teste de Tukey para a comparação entre médias $(P<0,05)$ e correlação entre as variáveis. Ao analisar os valores de PTS, globulinas, gamaglobulinas, IgG e atividade sérica de GGT ao nascimento (24 a 36 horas) pode se afirmar que houve adequada TIP não havendo diferença significativa entre as raças, exceto para a atividade sérica da GGT. Observaram-se variações fisiológicas na curva de proteínas séricas do nascimento até os 180 dias de idade. Forte correlação positiva foi observada entre os valores de gamaglobulina e IgG $(\mathrm{r}=0,814$ para $\mathrm{CL}$ e $r=0,877$ para AA), PTS $(r=0,783$ para CL e $r=0,947$ para AA), globulinas ( $r=0,945$ para CL e $r=0,985$ para AA), evidenciando que estas variáveis foram bons indicadores da TIP em bezerros ao segundo dia de vida (24-36 horas). A correlação entre gamaglobulinas e atividade da GGT foi fracamente positiva $(r=0,251)$ para bovinos da raça Crioula Lageana variedade mocha e fortemente positiva $(r=0,815)$ para a raça Aberdeen Angus (Red Angus), o qual foi admitido a grande variação nos valores da GGT após 24 horas de vida do bezerro. Não houve diferença na TIP entre as raças Crioula Lageana variedade mocha e Aberdeen Angus (Red
Angus), ocorrendo de maneira bem-sucedida em ambas as raças. Pode-se sugerir que a raça Crioula Lageana variedade mocha seja mais tardia na síntese ativa de anticorpos, ressaltando a precocidade dos taurinos evidenciada na raça Aberdeen Angus (Red Angus).

TERMOS DE INDEXAÇÃO: Bovino, imunoglobulinas, imunidade passiva, proteínas séricas.

\section{INTRODUÇÃO}

A raça Crioula Lageana descende dos bovinos ibéricos trazidos ao Brasil no início do século XVII, sob a tutela dos missionários jesuítas (Piazza 1983). Esses animais se espalharam pelas vacarias do sul (Serra Catarinense e Terceiro Planalto Paranaense) onde sofreram miscigenação (Mariante \& Cavalcante 2000). Durante aproximadamente 500 anos a raça foi submetida ao processo de seleção natural, permitindo a expressão de características específicas de adaptação às condições locais (Spritze 2001, Veiga et al. 2009). Durante longo período, os bovinos da raça Crioula Lageana foram à sustentação da bovinocultura da região do Planalto Serrano Catarinense (Mariante \& Cavalcante 2000), sendo que até o início do século XX, era a raça que predominava nos Campos da Região da Serra Catarinense (Spritze et al. 2003). Segundo Veiga et al. (2009), a raça Crioula Lageana apresenta características de interesse para produção animal, determinando uma importante alternativa para a pecuária moderna, devido a sua grande variabilidade genética, rusticidade e adaptação às condições ambientais do Planalto Catarinense. Existem duas variedades da raça Crioula Lageana, a aspada e a mocha. A variedade aspada é caracterizada pela presença de longos chifres, apresentado grande potencial para utilização no turismo rural, manutenção das tradições e culturas regionais, além da finalidade comercial, que na variedade mocha deve ser ainda maior, pela facilidade de manejo e transporte (Martins et al. 2009).

Com a corrente expansão da bovinocultura no Brasil, tem-se grande importância o índice de mortalidade neonatal (Rogers et al. 1985), sendo a falha da transferência da imunidade passiva (FTIP) um fator de grande contribuição para a elevação deste índice (Selim et al. 1995, Wittum \& Perino 1995). Esta falha pode ocorrer, na espécie bovina, devido à impossibilidade de transferência de imunoglobulinas através da placenta do tipo sindesmocorial (Tizard 2002). Após o nascimento, os bezerros expostos a agentes infecciosos do ambiente, adquirem estas imunoglobuli- 
nas por meio da ingestão do colostro materno, conferindo proteção imunitária eficaz nas fases iniciais da vida do bezerro (Besser \& Gay 1994, Fagliari et al. 1996, Borges 1997, Feitosa et al. 2001b, Bessi et al. 2002). Segundo Tizard (2002), existem três razões principais para que ocorra falha na transferência da imunidade passiva: a) produção insuficiente ou de má qualidade de colostro pela mãe; b) produção suficiente de colostro, mas com um consumo inadequado por parte do recém-nascido; c) falha na absorção intestinal apesar de um consumo adequado de colostro. Segundo Zanetti et al. (1982), o colostro é uma substância muito rica em imunoglobulinas, as quais sofrem maior absorção até 12 horas de vida. As imunoglobulinas colostrais absorvidas possuem uma meia-vida curta (21 dias para a IgG) na circulação dos bezerros recém-nascidos (Logan et al. 1972).

De forma geral, após o pico de concentração sérica às 24 horas de vida, observa-se redução progressiva até os 30 ou 45 dias de idade, quando se estabelece uma nova curva ascendente, que se deve à síntese ativa de anticorpos pelo sistema imunológico competente (Ribeiro et al. 1983, Moraes et al. 1997, Fagliari et al. 1998, Feitosa 1998, Costa 2000, Pauletti et al. 2003). Exames laboratoriais têm sido desenvolvidos para a determinação direta e/ou indireta da transferência de imunidade passiva (TIP), uma vez que os índices de mortalidade e um menor desempenho produtivo estão relacionados à FTIP (Feitosa et al. 2001b). No entanto são inexistentes os trabalhos que avaliem a TIP em bezerros das raças Crioula Lageana variedade mocha e Aberdeen Angus. Sendo assim, o presente trabalho teve como objetivo estudar e comparar aspectos fisiológicos relacionados à transferência de imunidade passiva e o proteinograma sérico em bezerros das raças Crioula Lageana variedade mocha e Aberdeen Angus (Red Angus), criados extensivamente no Planalto Serrano Catarinense, nos primeiros seis meses de vida.

\section{MATERIAL E MÉTODOS}

O projeto foi desenvolvido por uma equipe multidisciplinar e interinstitucional envolvendo a Universidade do Estado de Santa Catarina (UDESC), Universidade Estadual de Londrina (UEL) e a Associação Brasileira dos Criadores de Bovinos da Raça Crioula Lageana (ABCCL). O protocolo foi aprovado pelo Comitê de Ética em Experimentação Animal (CETEA) da UDESC sob número de registro $\mathrm{n}$-1.20.10. Foram selecionados aleatoriamente 25 bezerros aparentemente sadios ao nascimento e no primeiro dia de vida, produtos de partos eutócicos, os quais foram mantidos sob o mesmo manejo durante todo período experimental. Os animais foram obtidos de um Núcleo de Conservação in situ da raça Crioula Lageana e Aberdeen Angus localizado na Fazenda Bom Jesus do Herval no município de Ponte Alta, SC. Todos os bezerros ingeriram o colostro de forma espontânea (mamada natural), permanecendo em contato com suas mães durante todo o período do experimento, sob boas práticas de manejo nutricional e sanitário.

Os animais foram divididos em dois grupos experimentais de acordo com a raça, compostos por 11 animais da raça Crioula Lageana variedade mocha e 14 da raça Aberdeen Angus (Red Angus). Amostras de sangue foram colhidas de cada bezerro, por venopunção jugular externa, utilizando-se frascos a vácuo de $10 \mathrm{~mL}$ sem anticoagulante (Vacuum $\mathrm{II}^{\circledR}$, Labnew, São Paulo, Brasil), nas idades entre 24 e 36 horas, 15, 30, 60, 90, 120, 150 e 180 dias de vida. Após centrifugação o soro foi congelado a $20^{\circ} \mathrm{C}$ negativos e estocado até o momento das análises laboratoriais.

A determinação da concentração de proteínas totais séricas foi realizada pelo método de biureto segundo Jain (1993), utilizando-se reagentes comerciais (Laborlab, Produtos para Laboratório, Ltda EPP, São Paulo, Brasil). As concentrações séricas das frações proteicas albumina, alfa 1 , alfa 2, beta e gamaglobulinas foram determinadas por eletroforese (Kremers et al. 1967) utilizando gel de agarose (Celmgel, CELM gel de agarose geral), tampão Tris de pH 9,5 (CELM) e corrida eletroforética por 20 min em corrente de 100V (Sistema SE-250, CELM). Após o procedimento, o gel foi corado com negro de amido $2 \%$ e descorado com ácido acético 5\%. A proporção de cada fração proteica foi estabelecida por meio do programa de informática SDS-60 (CELM) do sistema SE-250 (CELM) após leitura realizada em scanner. A concentração sérica de imunoglobulinas $G$ foi estimada pela técnica de turvação pelo sulfato de zinco com leitura espectrofotométrica, conforme o método empregado por Pfeiffer et al. (1977) com modificações. Adicionou-se $0,1 \mathrm{~mL}$ de soro a $6 \mathrm{~mL}$ de uma solução contendo $208 \mathrm{mg}$ de $\mathrm{ZnSO}_{4} \cdot 7 \mathrm{H}_{2} \mathrm{O}$ por litro de água destilada. Após uma hora de repouso, a absorbância da mistura foi mensurada por espectrofotometria (Cintra 5, GBC Scientific Equipment) em comprimento de onda de $620 \mathrm{~nm}$. Devido à instabilidade da solução, foram realizadas três leituras e considerada a média final. A quantidade de IgG foi estimada com o uso de uma curva padrão previamente traçada com concentrações conhecidas de IgG bovina (Single Radial Immunodiffusion Kit; VRMD, EUA), a saber: zero (soro fetal bovino), 400, 800, 1600 e $3200 \mathrm{mg} / \mathrm{dL}$. As amostras que superaram o valor estimado de $3200 \mathrm{mg} / \mathrm{dL}$ foram processadas novamente após diluição do soro em solução fisiológica na proporção de 1:1. A atividade sérica da gamaglutamiltransferase foi determinada pelo método cinético colorimétrico segundo a técnica modificada de Szasz (1969), empregando-se reagentes comerciais (Laborlab) e leitura espectrofotométrica.

A análise estatística dos dados foi determinada por meio do teste de análise de variância de medidas repetidas (ANOVA) e o teste de Tukey para a comparação entre médias, admitindo-se uma probabilidade de erro de $5 \%$. Coeficientes de correlação foram estabelecidos entre as variáveis estudadas (Curi 1998).

\section{RESULTADOS E DISCUSSÃO}

Os valores de média e desvios-padrão referentes à proteína total sérica (PTS), albumina, alfa 1, alfa 2, beta e gamaglobulina, globulinas, relação albumina:globulinas (A:G), imunoglobulina G (IgG) e gamaglutamiltransferase (GGT) estão expostos no Quadro 1. Não houve diferença significativa $(P>0,05)$ para os valores médios da concentração de PTS, gamaglobulinas, globulinas e IgG no segundo dia de vida (24 a 36 horas) entre os grupos raciais (Quadro 1). Embora não significativos $(P>0,05)$, estes valores foram ligeiramente superiores para raça Crioula Lageana variedade mocha quando comparados à Aberdeen Angus (Red Angus).

Quanto à atividade sérica da GGT no segundo dia de vida (24 a 36 horas), observou-se diferença significativa $(P<0,05)$ entre raças, sendo maiores valores obtidos para a raça Crioula Lageana variedade mocha (Quadro 1). Costa et al. (2008) também observaram diferença racial quanto aos valores séricos da atividade da GGT em bezerros de corte, obtendo valores superiores para a raça Nelore em relação a Limousin. Teixeira et al. (2012) observaram TIP superior para a raça Crioula Lageana variedade aspada em relação 
Quadro 1. Valores médios e desvios-padrão $(\mathrm{x} \pm \mathrm{s})$ da concentração de proteína total sérica (PTS), albumina, alfa1, alfa-2, beta e gamaglobulinas, relação albumina:globulina (A:G), imunoglobulina G (IgG) e atividade da gamaglutamiltransferase (GGT) de bezerros das raças Crioula Lageana variedade Mocha e Aberdeen Angus (Red Angus) as 24-36h (M1), 15 (M2), 30 (M3), 60 (M4), 90 (M5), 120 (M6), 150 (M7) e 180 dias (M8) de vida

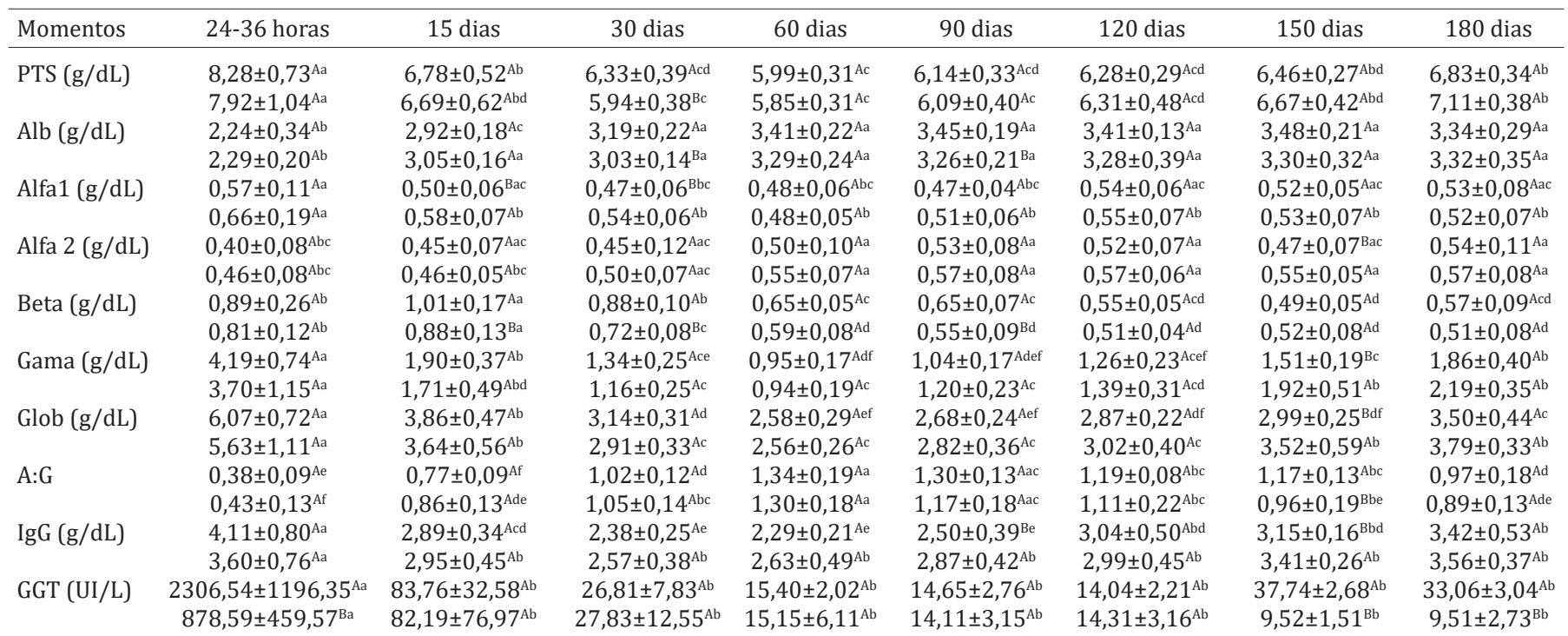

${ }^{A}$ Para letras maiúsculas iguais não há diferença significativa $(P>0,05)$ entre os grupos. a Para letras minúsculas iguais não há diferença significativa $(\mathrm{P}>0,05)$ entre os momentos.

raça Holandesa Preta e Branca, no entanto, os valores de IgG e GGT não diferiram significativamente. Apesar da diferença observada no presente trabalho ter sido significativa e de grande magnitude, não se considera superior a TIP para a raça Crioula Lageana variedade mocha em relação à Aberdeen Angus (Red Angus). Além da ampla variação nos valores individuais da GGT, deve-se levar em consideração que a diferença não foi acompanhada pelas outras variáveis analisadas, ocorrendo de maneira isolada.

A maior concentração de gamaglobulinas de acordo com a faixa etária foi verificada entre 24 a 36 horas de vida em ambas as raças (Quadro 1), estando relacionado com o pico de absorção de imunoglobulinas após a ingestão do colostro (Fagliari et al. 1996, Borges 1997, Feitosa et al. 2001b, Leal et al. 2003, Machado Neto et al. 2004, Costa et al. 2007, 2008, Vettorato et al. 2012, Teixeira et al. 2012). De acordo com observações realizadas por vários autores (Tennant \& Guerra 1969, Bouda \& Jagos 1984, Fagliari et al. 1991, Borges 1997, Feitosa 1998, Leal et al. 2003), valores mínimos de gamaglobulinas são observados entre o nascimento e oito horas pós-nascimento, sendo justificada pelas menores taxas de imunoglobulinas circulantes no bezerro ao nascimento (Kaneko \& Mills 1970).

A razão pela qual os bezerros nascem hipogamaglobulinêmicos é a impossibilidade de passagem transplacentária de gamaglobulinas ao feto (Fagliari 1988). Optou-se neste trabalho por realizar as colheitas somente após 24 horas de vida (entre 24 e 36 horas de vida) nunca antes, evitando assim a curva ascendente que antecede o pico de concentração sérica das imunoglobulinas (Fagliari et al. 1996, Borges 1997, Feitosa et al. 2001b, Leal et al. 2003, Machado Neto et al. 2004). As colheitas não foram realizadas antes da mamada do colostro para evitar rejeição dos bezerros recém-nascidos pelas suas mães e pela dificuldade de ma- nejo dos bovinos deste experimento, os quais eram criados extensivamente.

Analisando-se os valores médios referentes à concentração de PTS, globulinas, gamaglobulinas e IgG de acordo com a faixa etária, pode-se evidenciar redução contínua de seus valores em ambas as raças a partir do segundo dia de vida (24-36 horas) (Quadro 1). Esta redução ocorreu em consequência da degradação e a combinação das imunoglobulinas com antígenos (Costa et al. 2008), sendo este um processo fisiológico observado em bezerros (Feitosa et al. 2001b, Amorim 2002, Leal et al. 2003, Machado Neto et al. 2004). Valores mínimos foram encontrados em ambas as raças ao redor dos 60 dias de idade e aumentaram gradativamente até os 180 dias, corroborando com os resultados de outros autores em outras raças (Amorim 2002, Costa et al. 2008, Vettorato et al. 2012, Teixeira et al. 2012). Este gradual aumento deve-se a síntese ativa de anticorpos pelo sistema imune competente (Radostits et al. 2002). Costa et al. (2008) e Machado Neto et al. (2004) observaram influências raciais quanto aos valores da concentração de gamaglobulinas e IgG respectivamente, entre zebuínos e taurinos. Esta diferença ocorreu após 30 dias (Machado Neto et al. 2004) e 60 dias (Costa et al. 2008) de idade. Estes autores sugeriram que a síntese ativa de imunoglobulinas seja um processo mais tardio em zebuínos do que em taurinos de corte. Esta observação também foi realizada por outros autores em taurinos de raças leiteiras (Ribeiro et al. 1983, Borges 1997, Costa 2000, Feitosa et al. 2001a), onde estes bovinos apresentaram-se precoces em desenvolver imunidade ativa.

Tomando como padrão os valores da concentração de gamaglobulinas para comparação entre raças, não foram observadas diferenças significativas $(P>0,05)$, entre raças do segundo dia de vida (24-36 horas) até os 60 dias de 
idade. A raça Crioula Lageana variedade mocha obteve valores superiores nesta faixa etária, embora não significativos $(P>0,05)$, sendo que aos 60 dias os valores foram semelhantes. A partir dos 60 dias, observou-se elevação da concentração de gamaglobulinas em ambas as raças, sendo encontrados valores superiores para a raça Aberdeen Angus (Red Angus), evidenciando-se diferença significativa $(P<0,05)$ aos 150 dias de idade. Corroborando com Costa et al. (2008) este resultado demonstra a grande capacidade dos taurinos em desenvolver imunidade humoral ativa nesta faixa etária. Teixeira et al. (2012), observaram elevação mais precoce dos valores de gamaglobulina na raça Holandesa Preta e Branca em relação a Crioula Lageana variedade aspada, obtendo valores de maior magnitude e estatisticamente diferentes para a raça Holandesa Preta e Branca a partir dos 30 dias de idade. Os autores sugeriram que a raça Crioula Lageana variedade aspada possa ser mais tardia na síntese ativa de anticorpos. Dessa forma, esta pode ser uma característica da raça Crioula Lageana, presente em ambas as variedades. De maneira geral, admite-se que os bezerros estejam mais suscetíveis a contrair infecções no intervalo de tempo em que se mantêm as menores concentrações séricas de gamaglobulinas, período entre o término do processo de degradação de imunoglobulinas passivamente transferidas e a produção ativa pelo sistema imunológico competente (Radostits et al. 2002). No entanto, os animais apresentaram-se sadios durante todo o período experimental, o que demonstra que estes bezerros não estariam necessariamente mais suscetíveis a infecções, devido a esta particularidade, durante este período (Teixeira et al. 2012). Além disso, os mecanismos de defesa que garantem a saúde nesse período, não se restringem à imunidade humoral (Vettorato et al. 2012).

Os valores médios estimados de IgG obtidos às 24 e 36 horas de vida em ambas as raças investigadas (Quadro 1) encontraram-se muito superiores aos valores considerados críticos por muitos autores. Índices apontados como indicadores do sucesso incontestável da TIP variam de $1000 \mathrm{mg} / \mathrm{dL}$ (Radostits et al. 2002) a 1600mg/dL (McGuire \& Adams 1982). Valores de 500-1500mg/dL (Selim et al. 1995) e de 600-1600mg/dL (McGuire \& Adams 1982) podem ser indicativos de falha da transferência de imunidade passiva (FTIP) parcial. De acordo com Halliwell \& Gorman (1989) e Wittum \& Perino (1995), concentrações séricas de IgG maiores do que $1600 \mathrm{mg} / \mathrm{dL}$ são consideradas adequadas, concentrações de $800-1600 \mathrm{mg} / \mathrm{dL}$ valores marginais, e menores que $800 \mathrm{mg} / \mathrm{dL}$ como indicadores de FTIP. Levando em consideração os altos valores encontrados para IgG no primeiro dia de vida pode-se afirmar que houve sucesso na TIP em ambas as raças estudadas. De acordo com os resultados observados neste trabalho o teste de turvação pelo sulfato de zinco mostrou ser de fácil execução e de baixo custo, podendo ser utilizado como método de escolha para avaliação da TIP, corroborando com as afirmações realizadas por Feitosa (2001b). No entanto, tem seu uso restrito devido à necessidade do uso de equipamento específico (Moraes et al. 1997).

Quanto a relação albumina:globulinas (A:G) ocorreu maior variação ao longo do primeiro mês de vida em am- bas as raças (Quadro 1), sendo atribuída a flutuação da concentração destas proteínas neste período (Leal et al. 2003). Segundo Costa et al. (2008) alterações na relação A:G geralmente são o primeiro sinal de alteração no perfil eletroforético. Os valores médios da concentração de albumina foram menores ao segundo dia (24-36 horas), elevando-se até os 60 e 90 dias para as raças Aberdeen Angus (Red Angus) e Crioula Lageana variedade mocha, respectivamente. Esta elevação reflete um incremento na capacidade de síntese dessa proteína relacionado à idade (Kaneko 1997) e à ingestão de compostos nitrogenados na dieta (Costa et al. 2007). Os valores de gamaglobulinas encontraram-se elevados ao segundo dia de vida (24-36 horas) (Quadro 1) devido a absorção de IgG maternas pelo colostro (Costa et al. 2008, Garcia et al. 2012, Pires Júnior et al. 2013), para após reduzirem seus valores até os 60 dias de idade em ambas as raças. A inversão na relação A:G ocorreu em torno dos 30 dias, sendo o maior valor observado aos 60 dias de vida em ambas as raças estudadas, semelhante ao encontrado por Teixeira et al. (2012) em bovinos da raça Crioula Lageana variedade aspada. Observou-se diminuição nesta relação após os 60 dias de idade, o qual é atribuído à produção endógena de gamaglobulinas de acordo com Costa et al. (2008), os quais no entanto observaram inversão A:G em torno dos 15 dias de vida para as raças Nelore e Limousin.

Corroborando com observações de outros autores em outras raças (Costa et al. 2008, Teixeira et al. 2012, Vettorato et al. 2012), as frações alfa 1, alfa 2 e beta-globulinas não apresentaram variações expressivas ao longo do tempo e encontraram-se semelhantes em ambas as raças.

A determinação da atividade da GGT no soro de bezerros é utilizada como meio alternativo para avaliar a eficácia da TIP (Feitosa 1998, Radostits et al. 2002). Esta enzima está presente no fígado, rins e pâncreas, e sua determinação é utilizada como indicativo de alterações no sistema hepatobiliar em bovinos adultos (Kaneko 1997). De acordo com Radostits et al. (2002) as concentrações de GGT são altas no colostro de ruminantes, e a atividade sérica da GGT em bezerros que mamaram ou foram alimentados com colostro é 60 a 160 vezes maior do que a de adultos, havendo moderada correlação com as concentrações séricas de IgG. Isto ocorre devido à alta absorção desta enzima pelas células intestinais em bezerros recém-nascidos (Braun et al. 1982, Fagliari et al. 1996, Zanker et al. 2001). Sendo assim a determinação da atividade desta enzima no soro sanguíneo pode ser utilizada como método indireto de avaliação da transferência de imunidade passiva em neonatos ruminantes (Braun et al. 1978, Pires Júnior et al. 2013). De acordo com Radostits et al. (2002) valores de atividade sérica da GGT inferiores a 50UI/L indicam FTIP. No entanto, Paris et al. (1992) afirmaram que a atividade menor que 300UI/L está relacionada a baixas concentrações séricas de gamaglobulinas. No presente estudo a enzima apresentou valor máximo de atividade no soro das 24 às 36 horas de vida, decrescendo abruptamente nos primeiros 15 dias, até atingir valores fisiológicos em torno dos 60 dias de vida (Quadro 1), corroborando com os resultados obtidos por Costa et al. (2008) em bezerros Nelore e Limousin, e Teixeira et 
al. (2012) em bezerros das raças Crioula Lageana variedade aspada e Holandesa Preta e Branca. Delfino et al. (2014) observaram valores fisiológicos para a atividade da GGT aos 30 dias de idade em bezerros da raça Senepol. Segundo Radostits et al. (2002), a meia vida da GGT do colostro é curta, e a atividade da GGT sérica diminui significativamente na primeira semana de vida. Analisando-se os valores individuais da atividade sérica da GGT, foi observado que um animal da raça Aberdeen Angus (Red Angus) apresentou valor de 280,65UI/L, o qual, de acordo com a classificação proposta por Paris et al. (1992) seria considerado portador de FTIP. No entanto, excluiu-se esta possibilidade ao analisar que neste mesmo animal, os valores da concentração de PTS, gamaglobulinas, globulinas e IgG apresentaram valores considerados adequados à TIP. Também deve-se levar em consideração que este animal não apresentou qualquer enfermidade durante o período experimental. Este fato pode ter ocorrido devido ao momento da colheita de sangue deste animal, o qual ocorreu às 33 horas de vida, visto que o declínio da atividade da GGT no soro de bezerros antecede o da concentração das gamaglobulinas a partir das 24 horas de vida (Borges 1997).

Considerando os valores de gamaglobulinas como padrão para comparação, observarou-se ao término do primeiro dia de vida (24-36 h) forte correlação entre seus valores e os de IgG ( $\mathrm{r}=0,814$ para CL e $\mathrm{r}=0,877$ para AA), PTS $(r=0,783$ para $C L$ e $r=0,947$ para $A A)$, globulinas $(r=0,945$ para CL e $r=0,985$ para AA). Estes resultados reforçam afirmações anteriormente realizadas por Naylor \& Kronfeld (1977), Pfeiffer et al. (1997), Moraes et al. (1997), Feitosa et al. (2001a), Machado Neto et al. (2004), Costa et al. (2008) e Teixeira et al. (2012) nos quais estas variáveis foram bons indicadores da TIP em bezerros. A avaliação da TIP em bezerros após a ingestão do colostro tem como base a determinação direta de imunoglobulinas, ou indiretamente por meio das variáveis que apresentem correlação com os teores séricos das imunoglobulinas (Feitosa et al. 2010). Observou-se fraca correlação $(r=0,251)$ entre a gamaglobulina e atividade sérica da GGT para a raça Crioula Lageana variedade mocha e forte correlação $(r=0,815)$ para a raça Aberdeen Angus (Red Angus). Fato semelhante foi observado por Teixeira et al. (2012), em que obtiveram fraca correlação para a raça Crioula Lageana variedade aspada e forte correlação para a raça Holandesa Preta e Branca. Costa et al. (2008) também encontraram fraca correlação dessas variáveis em bovinos de corte. Segundo Borges (1997) a atividade sérica da GGT apresenta grande variabilidade e a partir das 24 horas de vida e o declínio de sua atividade antecede o da concentração das gamaglobulinas (Costa et al. 2008). Rocha et al. (2012) encontraram forte correlação entre GGT e globulinas no primeiro dia de vida em bezerros mestiços Canchim, no entanto, as colheitas de sangue foram realizadas às 24 horas após o nascimento. Sendo assim, forte correlação será encontrada, quanto mais próximo das 24 horas de vida as amostras forem colhidas. Desta forma, seria ideal que a colheita fosse realizada pontualmente às 24 horas de vida do animal, no entanto, devido a dificuldades operacionais o mesmo não foi realizado, sendo que parte das colheitas foram realizadas após 30 horas de vida. Con- dição semelhante foi observada por Costa et al. (2008) e Teixeira et al. (2012).

\section{CONCLUSÕES}

De acordo com o exposto neste trabalho, conclui-se que ao analisar-se os valores de PTS, globulinas, gamaglobulinas, IgG ao segundo dia de vida (24-36 horas) pode se afirmar que não houve diferença na TIP entre as raças Crioula Lageana variedade mocha e Aberdeen Angus (Red Angus).

A absorção de imunoglobulinas através do colostro foi adequada em ambas às raças estudadas.

Observaram-se variações fisiológicas nas concentrações das proteínas séricas do nascimento até os 180 dias de idade e a produção ativa de anticorpos foi mais tardia na raça Crioula Lageana variedade mocha, ressaltando a precocidade dos taurinos evidenciada na raça Aberdeen Angus (Red Angus).

A dosagem de gamaglobulina, IgG, PTS e globulinas, e a determinação da atividade sérica da GGT, foram bons indicadores da TIP em bezerros ao segundo dia de vida (24-36 horas).

Agradecimentos.- A Associação Brasileira dos Criadores de Bovinos da Raça Crioula Lageana (ABCCL) e aos proprietários da Fazenda Bom Jesus do Herval (Ponte Alta, SC).

\section{REFERÊNCIAS}

Amorim R.M. 2002. Valores séricos e hepáticos de elementos minerais, atividade sérica da ceruloplasmina, hemograma, proteinograma e metabolismo oxidativo dos neutrófilos em bezerros da raça Nelore, nascidos de mães com nutrição adequada ou inadequada em cobre e zinco. Tese de Doutorado em Clínica Veterinária, Faculdade de Medicina Veterinária e Zootecnia, Universidade Estadual Paulista, Botucatu, SP. 158p.

Besser T.E. \& Gay C.C. 1994. The importance of colostrum to the health of the neonatal calf. Vet. Clin. North Am., Food Anim. Pract. 10(1):107-117.

Bessi R., Pauletti P., d’Arce R.C. \& Machado Neto R. 2002. Absorção de anticorpos do colostro em bezerros I. Estudo no intestino delgado proximal. Revta Bras. Zootec. 31(6):2314-2324.

Borges A.S. 1997. Avaliação da eficácia da administração de plasma, por via intravenosa, como tratamento da falência de transferência de imunidade passiva em bezerros da raça Holandesa. Dissertação de Mestrado em Clínica Veterinária, Faculdade de Medicina Veterinária e Zootecnia, Universidade de São Paulo, São Paulo/SP. 84p.

Bouda J. \& Jagos P. 1984. Biochemical and hematological reference values in calves and their significance for health control. Acta Vet. Brno 53(3):193-198.

Braun J.P., Rico A.G., Benard P., Thouvenot J.P. \& Bonnefis M.J. 1978. Blood and tissue distribution of gamma glutamyl transferase in calves. J. Dairy Sci. 61:596-599.

Braun J.P., Tainturier D., Laugier C., Bénard P., Thouvenot J.P. \& Rico A.G. 1982. Early variations of blood plasma gamma-glutamyl transferase in newborn calves: A test of colostrum intake. J. Dairy Sci. 65(11):21782181.

Costa J.N. 2000. Leucograma, metabolismo oxidativo dos neutrófilos, proteinograma e imunoglobulinas de bovinos da raça holandesa (Bos taurus). Influência do desenvolvimento etário e da suplementação com vitamina E (acetato de DL-alfa-tocoferol). Tese de Doutorado em Clínica Veterinária, Faculdade de Medicina Veterinária e Zootecnia, Universidade Estadual Paulista, Botucatu, SP. 209p.

Costa J.N., Peixoto A.P.C., Kohayagawa A. \& Souza T.S. 2007. Proteinograma sérico de bezerras da raça Holandesa do nascimento aos 150 dias de idade. Revta Bras. Saúde Prod. Anim. 8(4):267-275.

Costa M.C., Flaiban K.K.M.C., Coneglian M.M., Feitosa F.L.F., Balarin M.R.S. 
\& Lisboa J.A.N. 2008. Transferência de imunidade passiva em bezerros das raças nelore e limousin nos primeiros quarto meses de vida. Pesq. Vet. Bras. 28(9):410-416.

Curi P.R. 1998. Metodologia e análise da pesquisa em ciências biológicas. $2^{a}$ ed. Gráfica e Editora Tipomic, Botucatu. 263p.

Delfino J.L., Barbosa V.M., Gondim C.C., Oliveira P.M., Nasciutti N.R., Oliveira R.S.B.R., Tsuruta S.A., Mundim A.V. \& Saut J.P.E. 2014. Perfil bioquímico sérico de bezerros Senepol nos primeiros 120 dias de idade. Semina, Ciênc. Agrárias 35(3):1341-1350.

Fagliari J.J., Oliveira E.C., Pegorer M.F., Ferrante Júnior L.C. \& Campos Filho E. 1996. Relação entre o nível sérico de gamaglobulinas e as atividades de gama glutamiltransferase, fosfatase alcalina e aspartato aminotransferase de bezerros recém-nascidos. Arq. Bras. Med. Vet. Zootec. 48(2):105-112.

Fagliari J.J., Passipieri M. \& Okuda H.T. 1991. Valores de referência das proteínas séricas de bovinos Guzerá em diferentes faixas etárias. Arq. Bras. Med. Vet. Zootec. 43(1):39-60.

Fagliari J.J., Passipieri M., Curi P.R., Ferreira Neto J.M. \& Lucas A. 1988. Valores padrões das proteínas séricas de bovinos da raça Guzerá. II. Proteinograma sérico de bezerros recém-nascidos. Ars Vet. 4:225-232.

Fagliari J.J., Santana A.E., Lucas F.A., Campos Filho E. \& Curi P.R. 1998. Constituintes sangüíneos de bovinos recém-nascidos das raças Nelore (Bos indicus) e Holandesa (Bos taurus) e de bubalinos (Bubalis bubalus) da raça Murrah. Arq. Bras. Med. Vet. Zootec. 50(3):253-62.

Feitosa F.L.F. 1998. Dinâmica do proteinograma e da atividade da gama glutamiltransferase no soro sangüíneo de bezerros desde o nascimento até um ano de vida e de vacas antes e após o parto, da raça holandesa. Tese de Doutorado em Clínica Veterinária, Faculdade de Medicina Veterinária e Zootecnia, Universidade de São Paulo, São Paulo/ SP. 219p.

Feitosa F.L.F., Birgel E.H., Mirandola R.M.S. \& Perri S.H.V. 2001a. Proteinograma sérico de bezerros holandeses do nascimento até um ano de vida. Revta Bras. Ciênc. Vet. 8(2):105-108.

Feitosa F.L.F., Birgel E.H., Mirandola R.M.S. \& Perri S.H.V. 2001b. Diagnóstico de falha de transferência de imunidade passiva em bezerros através da determinação de proteína total e de suas frações eletroforéticas, imunoglobulinas $\mathrm{G}$ e $\mathrm{M}$ e da atividade da gama glutamiltransferase no soro sanguíneo. Ciência Rural 31(2):251-255.

Feitosa F.L.F., Camargo D.G., Yanaka R., Mendes L.C.N., Peiró J.R., Bovino F., Lisboa J.A.N., Perri S.H.V. \& Gasparelli E.R.F. 2010. Índices de falha de transferência de imunidade passiva (FTIP) em bezerros holandeses e nelores, às 24 e 48 horas de vida: valores de proteína total, de gamaglobulina, de imunoglobulina $\mathrm{G}$ e da atividade sérica de gamaglutamiltransferase, para o diagnóstico de FTIP. Pesq. Vet. Bras. 30(8):696-704.

Garcia R.A.S., Werner O., Barca Junior F.A., Silva L.C., Cunha Filho L.F.C., Lisboa J.A.N., Balarin M.R.S. \& Headley S.A. 2012. Evalution of the transfer of passive immunity by the analysis of immunoglobulin and serum proteins of Holstein calves. Semina, Ciênc. Agrárias 33(4):1515-1520.

Halliwell R.E.W. \& Gorman N.T. 1989. Veterinary Clinical Immunology. W.B. Saunders, Philadelphia. 548p.

Jain N.C. 1993. Essentials of Veterinary Hematology. Lea and Febiger, Philadelphia. 417p.

Kaneko J. J. \& Mills R. 1970. Hematological and blood chemical observations in neonatal normal and porphyric calves in early life. Cornell Vet. 60(1):52-60.

Kaneko J.J., Harvey J.W. \& Bruss M.L. 1997. Clinical Biochemistry of Domestic Animals. 5th ed. Academic Press, San Diego, p.117-138.

Kremers B., Briere R. \& Batsakis J.G. 1967. Reflectance densitometry of cellulose acetate protein eletrophoresis. Am. J. Med. Technol. 33(1):2834.

Leal M.L.R., Benesi F.J., Lisbôa J.A.N., Coelho C.S. \& Mirandola R.M.S. 2003. Proteinograma sérico de bezerras sadias, da raça holandesa, no primeiro mês pós-nascimento. Braz. J. Vet. Res. Anim. Sci. 40(2):138-145.

Logan E.F., Penhale W.J. \& Jones R.A. 1972. Changes in the serum immunoglobulins of colostrum fed calves during the first twelve weeks postpartum. Res. Vet. Sci. 14(3):394-397.
Machado Neto R., Packer I.U., Prado G.V.B., Bessi R. \& Pauletti P. 2004. Colostral immunoglobulins absorption in Canchim and Nelore calves. Revta Bras. Zootec. 33(6):1544-1547.

Mariante A.S. \& Cavalcante N. 2000. Animais do Descobrimento: raças domésticas da história do Brasil. Embrapa-Cenargen, Brasília. 232p.

Martins V.M.V., Veiga T.F., Martins E., Quadros S.A.F., Cardoso C.P. \& Ribeiro J.A.R. 2009. Raça Crioula Lageana. 0 esteio do ontem, o labor do hoje e a oportunidade do amanhã. Editora Associação Brasileira dos Criadores da Raça Crioula Lageana (ABCCL), Lages. 98p.

McGuire T.C. \& Adams D.S. 1982. Failure of colostral immunoglobulin transfer to calves: Prevalence and diagnosis. Compend. Contin. Educ. Pract. Vet. 4(1):35-40.

Moraes M.P., Weiblen R., Silva A.M. \& Tobias F.L. 1997. Evolução da imunidade passiva em fêmeas bovinas da raça Holandesa. Ciência Rural 27(3):435-40.

Naylor J.M., Kronfeld D.S., Bech-Nielsen S. \& Bartholomew R.C. 1977. Plasma total protein measurement for prediction of disease and mortality in calves. J. Am. Vet. Med. Assoc. 171(7):635-638.

Paris T.N.N., Quedraogo G., Rico A.G., Bezzile P. \& Braun J.P. 1992. Interêt de la gamma-glutamyl transférase sérique et de la protidêmie totale pour le controle de la prise colostrale chez les veaux nouveaunés. Rec. Méd. Vet. 168:43-47.

Pauletti P., Machado Neto R., Packer I.U., d'Arce R.D. \& Bessi R. 2003. Quality of colostral passive immunity and pattern of serum protein fluctuation in newborn calves. Scientia Agricola 60(3):453-456.

Pfeiffer N.E., McGuire T.C., Bendel R.B. \& Weikel J.M. 1977. Quantitation of bovine immunoglobulins: comparison of single radial immunodiffusion, zinc sulfate turbidity, serum electrophoresis, and refratometer methods. Am. J. Vet. Res. 38(5):693-698.

Piazza W.F. 1983. Santa Catarina: Sua história. $19^{a}$ ed. UFSC Lunardelli, Florianópolis. 750p.

Pires Júnior J.B., Buonora C.R.A.R., Afonso A.B., Dantas F.R., Pereira A.L.L., Vieira A.C.S. \& Mendonça C.L. 2013. Transferência de imunidade passiva em bezerros oriundos de partos distócicos obtidos por cesariana. Rev. Bras. Med. Vet. 35(2):111-116.

Radostits O.M., Gay C.C., Blood D.C. \& Hinchcliff K.W. 2002. Clínica Veterinária: Um tratado de doenças dos bovinos, ovinos, suínos, caprinos e equinos. 9a ed. Guanabara Koogan, Rio de Janeiro, p.102-136.

Ribeiro M.F.B., Salcedo J.H.P., Belém P.A.D. \& Faria J.E. 1983. Hipogamaglobulinemia em bezerros. Arq. Bras. Vet. Zootec. 35(4):537-546.

Rocha T.G., Niciti R.P., Sampaio A.A.M. \& Fagliari J.J. 2012. Passive immunity transfer and serum constituents of crossbred calves. Pesq. Vet. Bras. 32(6):515-522.

Rogers R.W., Martin S.W. \& Meek A.H. 1985. Reproductive efficiency and calf survival in Ontario bovine cow-calf herds: A cross sectional mail survey. Can. J. Comp. Med. 49(1):27-33.

Selim S.A., Smith B.P. \& Cullor J.S. 1995. Serum immunoglobulins in calves: their effects and two easy reliable means of measurement. Vet. Med. 90:387-404.

Spritze A. 2001. Uso de marcadores moleculares RAPD na caracterização genética da raça bovina Crioulo Lageano. Dissertação de Mestrado em Ciências Agrárias, Universidade de Brasília, Brasília, DF. 67p.

Spritze A., Egito A.A., Mariante A.S. \& McManus C. 2003. Caracterização genética da raça bovina Crioulo Lageano por marcadores moleculares RAPD. Pesq. Agropec. Bras. 38(10):1157-1164.

Szasz G. 1969. A kinetic photometric method for serum gamma-glutamyl transpeptidase. Clin. Chem. 15(2):124-136.

Teixeira W.T., Fonteque G.V., Ramos A.F., Mariante A.S., Egito A.A., Martins V.M.V., Saito M.E. \& Fonteque J.H. 2012. Transfer of passive immunity and serum proteinogram in the first six months of life of Criollo Lageano and Black and White Holstein calves. Pesq. Vet. Bras. 32(10):980986.

Tennant B. \& Guerra M.R. 1969. Neonatal alterations in serum gamaglobulin levels of Jersey and Holstein-Friesian calves. Am. J. Vet. Res. 51(2):345-354. 
Tizard I.R. 2002. Imunologia Veterinária: uma introdução. $6^{a}$ ed. Roca, São Paulo. 120p.

Veiga T.F., Quadros S.A.F., Martins E. \& Improta C.T.R. 2009. Raça Crioula Lageana: percepções em relação às possibilidades de sua exploração na região do planalto catarinense. Revta Bras. Agroec. 4(1):29-38.

Vettorato E.D., Costa M.C., Flaiban K.K.M.C., Vidotto O., Balarin M.R.S. \& Lisbôa J.A.N. 2012. Variação de proteínas séricas em bezerros das raças nelore e holandesa do nascimento até os seis meses de vida. Semina, Ciênc. Agrárias 33(2):3181-3190.

Wittum T.E. \& Perino L.J. 1995. Passive immune status at postpartum hour 24 and long-term health and performance of calves. Am. J. Vet. Res. 56(9):1149-1154.

Zanetti M.A., Lucci C.S. \& Lobo R.B. 1982. Duração do período de absorção de imunoglobulina do colostro por bezerros recém-nascidos. Revta Soc. Bras. Zootec.11(4):612-621.

Zanker I.A., Hammon H.M. \& Blum J.W. 2001. Activities of y-glutamyltransferase, alkaline phosphatase and aspartate-aminotransferase in colostrum, milk and blood plasma of calves fed first colostrum at 0-2, 6-7, 12-13 and 24-25 h after birth. J. Vet. Med. A, Physiol. Pathol. Clin. Med. 48(3):179-185. 